\title{
Stage IVA Bone Sarcoma AJCC v7
}

National Cancer Institute

\section{Source}

National Cancer Institute. Stage IVA Bone Sarcoma AJCC V7. NCI Thesaurus. Code

C6707.

Stage IVA includes: Any T, N0, M1a, Any G. N0: No regional lymph node metastasis. M1a:

Distant metastasis to lung. (AJCC 7th ed.) 